\title{
TRENDS
}

\section{The Quantity And Quality Of Worldwide New Drug Introductions, 1982-2003}

\author{
The United States has taken the lead worldwide in innovative \\ performance and as a first-launch location for new drug introductions.
}

\section{by Henry G. Grabowski and Y. Richard Wang}

ABSTRACT: We examined trends in the introduction of new chemical entities (NCEs) worldwide from 1982 through 2003. Although annual introductions of NCEs decreased over time, introductions of high-quality NCEs (that is, global and first-in-class NCEs) increased moderately. Both biotech and orphan products enjoyed tremendous growth, especially for cancer treatment. Country-level analyses for 1993-2003 indicate that U.S. firms overtook their European counterparts in innovative performance or the introduction of first-in-class, biotech, and orphan products. The United States also became the leading market for first launch. [Health Affairs 25, no. 2 (2006): 452-460; 10.1377/hlthaff.25.2.452]

I N THE 198 os some scholars and scientific organizations raised concerns that the UU.S. pharmaceutical industry, along with other research-intensive sectors, was losing its leadership position to the Japanese and European industries. ${ }^{1}$ The concerns were based on an examination of new drug introductions, patent counts, and growth rates of research and development (R\&D) spending. However, a closer analysis of these data underscored the importance of considering measures of drug output based on commercial importance and innovativeness rather than on simple counts of new drug introductions and patents.

One measure that subsequently received particular attention was the concept of "consensus" or "global" new chemical entities (NCEs). Global NCEs are drugs introduced in a majority of the world's leading drug mar- kets. ${ }^{2}$ Although an average of just over fifty NCEs per year were introduced worldwide from 1970 through 1983, only 24 percent of these were introduced into a majority of the world's eleven largest markets. ${ }^{3}$

U.S. firms were the dominant source of global NCE introductions from 1970 through 1983 (41.7 percent), yet they accounted for a much smaller percentage of total NCEs relative to Japanese and European firms. ${ }^{4}$ L.G. Thomas examined why firms from countries such as Japan and France had high rates of NCE introductions only into the home country or a few neighboring countries. ${ }^{5}$ His explanation focused on the innovation incentives spawned by public policies in the home countries, such as support for biomedical research and regulations affecting new drug availability and prices. More recently, Alfonso Gambardella and colleagues examined the in-

Henry Grabowski (grabow@econ.duke.edu) is a professor of economics in the Department of Economics, Duke University, in Durham, North Carolina. Richard Wang is director of health services research and policy analysis at AstraZeneca Pharmaceuticals in Wilmington, Delaware, and an adjunct senior fellow at the Leonard Davis Institute of Health Economics, University of Pennsylvania, in Philadelphia. 
ternational competitiveness of European firms and found a relative decline in innovativeness as measured by patent citations. ${ }^{6}$ They attributed the decline in large part to public policies toward industry that are now prevalent in $\mathrm{Eu}$ rope.

Global NCEs are preferred to total NCEs as a measure of output because they are a more selective indicator of a drug's commercial and therapeutic importance. At the same time, this measure also might reflect the multinational structure and marketing capacity of the originating organization. Additional measures used to weigh pharmaceutical output for quality include product revenues, patent citations, and citations in medical journals and textbooks. ${ }^{7}$

Here we consider several complementary output measures that reflect various quality attributes. We give particular attention to novel or "first-in-class" drugs. ${ }^{8}$ We also focus on biotech and orphan drugs, given their increasing importance in this industry. Furthermore, we examine the country of first launch, which is receiving renewed interest because of current developments in regulatory and trade policies.

\section{Structural Changes In The Pharmaceutical Sector}

A new analysis of the trends and sources of new drug introductions is warranted for a number of reasons. First, recent studies have highlighted the declining number of new drug introductions since the mid-1990s. ${ }^{9}$ However, if a declining trend in introductions is associated with higher drug quality (that is, if there is a trade-off between quantity and quality), then some of the concerns about current NCE introduction levels and declining $R \& D$ productivity might be allayed.

Second, important structural developments have taken place in the drug industry during the past two decades. The biotech industry was in its infancy in the early 1980s but is now a major source of innovation and overall industry growth. ${ }^{10}$ Another development was the passage of the U.S. Orphan Drug Act in 1983, followed by similar laws in Europe and Japan. These laws encourage R\&D of drugs for relatively rare diseases-so-called orphan drugs. Most orphan drugs target diseases with high unmet medical needs, so they have received priority ranking by the U.S. Food and Drug Administration (FDA) and others."

"Drug lag" studies of introductions in the 1970s and 1980s found that the United States was seldom the country of first launch. ${ }^{12}$ This was true despite the fact that the United States is the largest pharmaceutical market and that many NCEs originated in U.S. firms. However, the Prescription Drug User Fee Act (PDUFA) of 1992 and the FDA Modernization Act (FDAMA) of 1997 provided various incentives and reforms to accelerate the drug review process. ${ }^{13}$ These reforms and subsequent declines in approval times have removed a key barrier to first launch in the United States. ${ }^{14}$ There is also a common approval option now available in the European Union (EU) and a movement to harmonize drug approval requirements..$^{15}$ Japan so far remains largely outside this harmonization movement.

The U.S. drug market has also grown much more rapidly than those of Europe and Japan during the past decade, which is a reflection of different attitudes and approaches toward rewarding innovation and controlling drug costs. ${ }^{16}$ In the United States, new drugs sell at premium prices and constitute a much higher allocation of total prescription dollar sales. In contrast, most European countries and Japan have single-payer purchasing regimes and various forms of price and spending controls that extend to both new and old drugs. Accordingly, these countries have much smaller generic sectors. ${ }^{17}$

We would expect that the combination of lower regulatory barriers and a marketoriented approach to the pricing of new drugs make the United States the most attractive place to launch new pharmaceuticals. Recent studies of new drug launches provide some preliminary evidence..$^{18}$ In this study we were particularly interested in analyzing the launch patterns for new drugs of commercial and therapeutic importance. 


\section{Study Data And Methods}

Using the New Product Focus database (IMS Health Inc., Fairfield, CT), we identified all NCEs first introduced worldwide between 1982 and 2003. The database reports all drug launches in sixty-eight countries since January 1982 (up to June 2004 in our version).

IMS Health defines NCEs based on the first international launch of a new active substance, also including new biological products (specifically recombinant proteins and recombinant vaccines). We use this expanded definition throughout the paper. The definition explicitly excludes diagnostic tests (except for radiopaques), radiologicals, over-the-counter products, combination vaccines, polyclonal antibodies, and biological extracts. The definition contrasts with the FDA category "new molecular entities" (NMEs), which is based on the first marketing approval of an active substance in the United States and includes diagnostics as well as other categories. ${ }^{19}$

We examined each NCE's dissemination in the G7 countries (Canada, France, Germany, Italy, Japan, the United Kingdom, and the United States). We defined global NCEs as those introduced in at least four of the G7 countries (the world's largest pharmaceutical markets). ${ }^{20}$ Therefore, our defined global NCEs represent high-quality or commercially important NCEs, or both. This definition of global NCEs is biased against recently introduced NCEs due to right censoring - that is, less time for recent NCEs to launch in at least four of the G7 countries.

We also identified the first NCE in a therapeutic class (defined as the unique combination of the five-digit Uniform System of Classification, USC, and the four-level Anatomical Therapeutic Classification, ATC, system). ${ }^{21}$ We used the U.S. National Disease and Therapeutic Index for September 2003-August 2004 (IMS Health) to obtain the USC and ATC classifications. NCEs not yet available in the United States were ineligible for first-in-class designation, because we could not identify similar databases for other countries that contain both classifications. ${ }^{22}$

In addition, we focused on two NCE cate- gories of policy interest: biotech products and orphan products. We defined an orphan product as an NCE launched in the United States within six months after FDA approval of its earliest orphan indication. This excludes NCEs that gained orphan indications after launch. We excluded orphan products not yet available in the United States.

We defined the corporation that first launched an NCE in the database as its developer and assigned its headquarters country as the NCE's nationality. ${ }^{23}$ If more than one firm first launched an NCE, each received an equal share of that NCE for nationality assignment purposes. ${ }^{24}$ Finally, we tracked changes in NCE first-launch country over time. If more than one country experienced an NCE's first launch, each received an equal share of that NCE as its first-launch market.

\section{Study Results}

We first analyzed the dissemination across the G7 countries of five NCE categories: all NCEs, global NCEs, first-in-class NCEs, biotech products, and orphan products. For each category, we next considered time trends for 1982-2003. We then examined the distribution of NCEs across therapeutic areas, the nationalities of the firms developing the NCEs, and the countries of first launch. We also separated the 1982-2003 period into two elevenyear periods to compare changes over time.

- Summary statistics and time trends. A total of 919 NCEs were introduced from 1982 through 2003 (Exhibit 1). Of these, 42 percent were global NCEs, 13 percent were first-in-class NCEs, 10 percent were biotech products, and 8 percent were orphan products. Only 14 percent were disseminated in all of the G7 countries. First-in-class NCEs, biotech products, and orphan products were more likely to be global products-76 percent, 56 percent, and 61 percent, respectively. ${ }^{25}$

NCEs exhibited a more global character over time. Despite the presence of right censoring, 47 percent of all NCEs were introduced in a majority of the $G 7$ countries from 1993 through 2003, compared with 37 percent during 1982-1992 and only 24 percent during 
EXHIBIT 1

Dissemination Of New Chemical Entities (NCEs), By Category, In The G7 Countries, 1982-2003

\begin{tabular}{lccccc}
\hline $\begin{array}{l}\text { Number of } \\
\text { G7 countries }\end{array}$ & All NCEs & Global NCEs & $\begin{array}{l}\text { First-in-class } \\
\text { NCEs }\end{array}$ & $\begin{array}{l}\text { Biotech } \\
\text { NCEs }\end{array}$ & $\begin{array}{l}\text { Orphan } \\
\text { NCEs }\end{array}$ \\
\hline 0 & 48 & 0 & 0 & 2 & 0 \\
1 & 336 & 0 & 13 & 28 & 16 \\
2 & 89 & 0 & 9 & 7 & 7 \\
3 & 61 & 0 & 6 & 3 & 4 \\
\hline 4 & 69 & 69 & 7 & 13 & 8 \\
5 & 70 & 70 & 16 & 16 & 15 \\
6 & 119 & 119 & 24 & 12 & 8 \\
7 & 127 & 127 & 40 & 9 & 11 \\
\hline Total & 919 & 385 & 115 & 90 & 69 \\
\hline
\end{tabular}

SOURCE: Authors' own analyses.

1970-1983 (in a previous study). ${ }^{26}$

There was a downward trend in all NCE introductions (Exhibit 2), which was generally consistent with analyses of U.S. introductions. ${ }^{27}$ Annual introductions of NCEs peaked in 1985-1988 and declined afterward, reaching a smaller peak in 1997. However, the time trend in global NCEs is upward except in the last few years (which have the right-censoring problem) ${ }^{28}$ Most importantly, first-in-class introductions exhibited a moderate increase over time, except for a few outliers since 1993.

The trends suggest that NCEs' relative quality has increased over time. If we split the study period into two eleven-year intervals, 52 percent of NCEs were introduced in the first period, but only 46 percent of first-in-class and global NCEs were introduced in this pe-

\section{EXHIBIT 2}

Annual Introduction Of New Chemical Entities (NCEs), By Category, 1982-2003

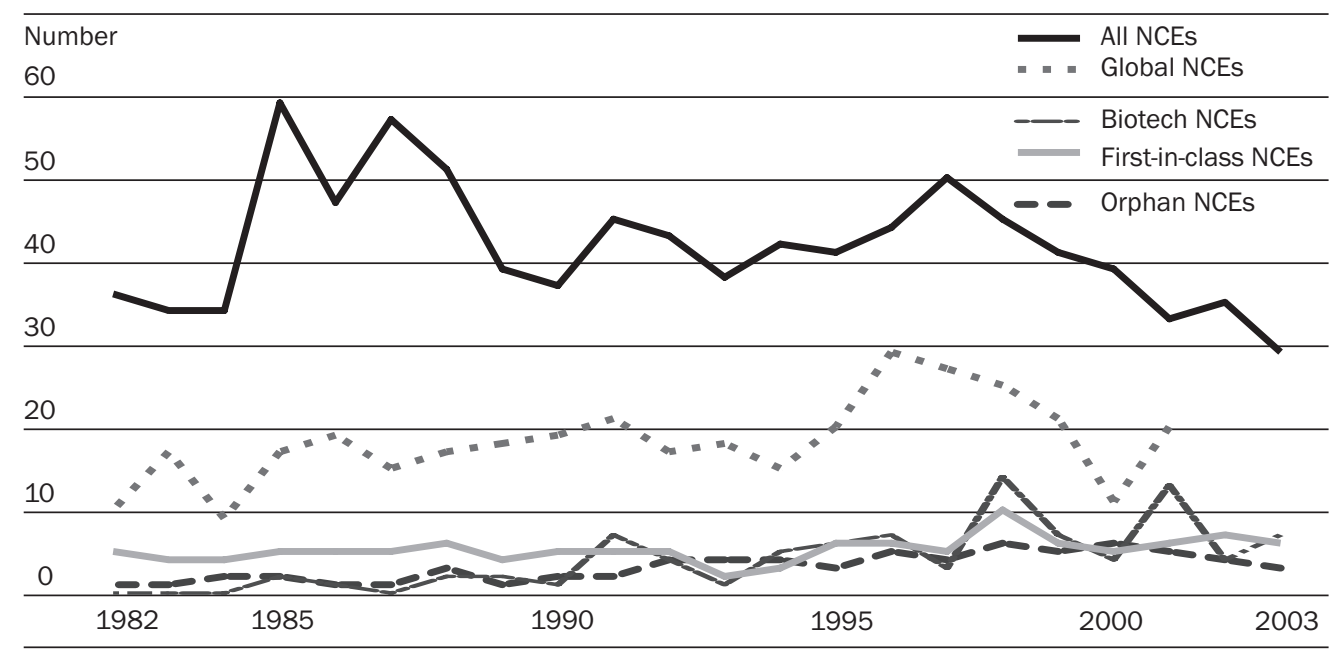

SOURCE: Authors' own analyses.

NOTES: Data for 2002 and 2003 for global NCEs are omitted, given that the mean time for an NCE to achieve global status was twenty-four months in the late 1990s. Through June 2004, the number of global NCEs for 2002 was thirteen, and for 2003 it was seven. 
riod. Both biotech and orphan products enjoyed tremendous growth over time, with 79 percent of biotech products and 71 percent of orphan products introduced during 19932003.

NCE introductions across therapeutic categories. Of all NCEs, there was a virtual tie among the top three therapeutic areascardiovascular (128), systemic anti-infective (127), and central nervous system (CNS) (130) (data not shown). These are also the three largest categories historically in terms of industry R\&D spending. ${ }^{29}$ However, NCEs' quality varied greatly by therapeutic area. Only 35 percent of cardiovascular NCEs were global, and only 5 percent were first-in-class. By contrast, 53 percent of oncology drugs were global, and 21 percent were first-in-class. Oncology also ranked first in introductions of first-in-class NCEs and biotech and orphan products.

Therapeutic-area distributions also differed by region. In global NCE introductions, Japanese firms concentrated more on systemic anti-infective agents (mainly antibiotics) and respiratory drugs, and less on oncology or CNS drugs, than EU or U.S. firms. The three leading areas for EU firms were CNS, oncology, and cardiovascular; the leading areas for U.S. firms were systemic anti-infective agents (including antivirals), oncology, and CNS.

- NCE output by firm nationality. When we considered European countries as a whole, the firms had similar proportions of global NCEs compared with U.S. firms (Exhibit 3). U.S. firms had higher proportions of first-inclass NCEs and biotech and orphan drugs. Japanese firms were less innovative than either EU or U.S. firms on these measures. There were also notable differences across countries. In particular, Swiss and British firms had percentages of first-in-class drugs similar to those of U.S. firms, whereas firms from Japan and Italy were in the lowest tier.

Observed differences across countries between the 1982-1992 and 1993-2003 periods are noteworthy (Exhibit 4). U.S. firms gained in every NCE category; EU firms experienced similar gains except in total number of NCEs. EU firms accounted for 54 percent of global NCEs; U.S. firms accounted for 39 percent. Japan and the rest of the world accounted for the remaining 7 percent.

U.S. leadership in first-in-class, biotech, and orphan drugs was more pronounced during 1993-2003, accounting for 48 percent of first-in-class, 52 percent of biotech, and 55 percent of orphan NCEs. ${ }^{30}$ Aside from U.S. firms, Swiss and British firms accounted for the most first-in-class NCEs, Japanese and Swiss firms had the most biotech drugs, and Swiss firms led in orphan compounds.

Country of first launch. U.S. firms

\section{EXHIBIT 3}

Characteristics Of New Chemical Entity (NCE) Output, By Region And Major Country, 1982-2003

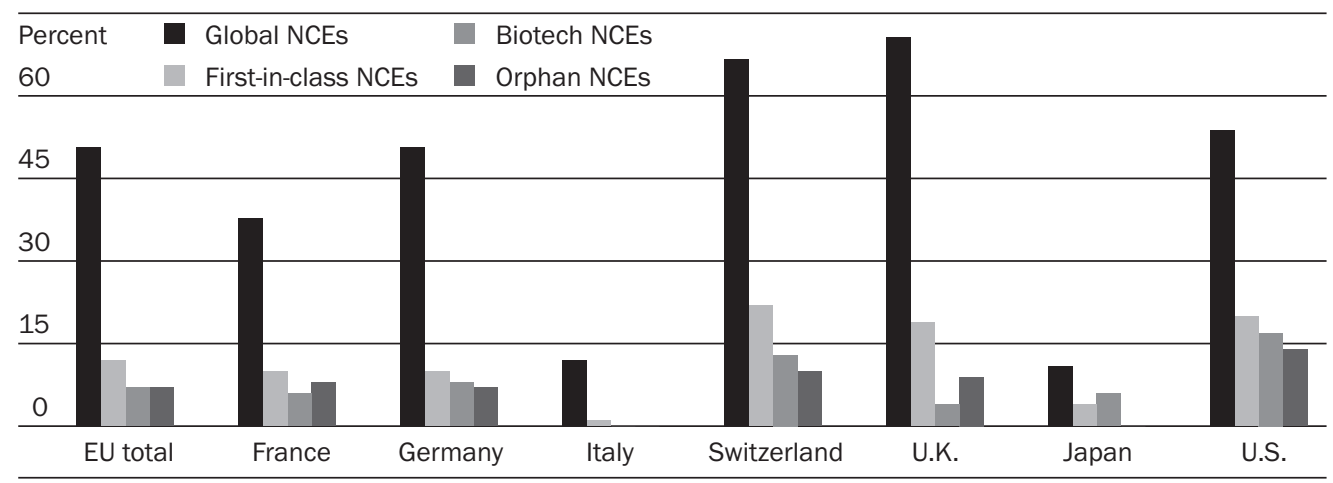

SOURCE: Authors' own analyses.

NOTE: EU is European Union. 
EXHIBIT 4

Country-Level Output Of New Chemical Entities (NCEs) By Category And Time Period, 1982-1992 and 1993-2003

\begin{tabular}{|c|c|c|c|c|c|c|c|c|c|c|}
\hline \multirow[b]{2}{*}{ Country } & \multicolumn{2}{|c|}{ All NCEs } & \multicolumn{2}{|c|}{ Global NCEs } & \multicolumn{2}{|c|}{ First-in-class NCEs } & \multicolumn{2}{|c|}{ Biotech NCEs } & \multicolumn{2}{|c|}{ Orphan NCEs } \\
\hline & 82-92 & $93-03$ & 82-92 & 93-03 & 82-92 & 93-03 & 82-92 & $93-03$ & 82-92 & $93-03$ \\
\hline EU total & 230 & 183 & 99 & 112 & 23 & 27 & 6 & 23 & 9 & 20 \\
\hline France & 35 & 18 & 9 & 11 & 2 & 3 & 0 & 3 & 0 & 4 \\
\hline Germany & 53 & 42 & 21 & 27 & 5 & 5 & 2 & 6 & 2 & 5 \\
\hline Italy & 29 & 14 & 4 & 1 & 1 & 0 & 0 & 0 & 0 & 0 \\
\hline Switzerland & 42 & 41 & 26 & 30 & 8 & 11 & 3 & 8 & 1 & 8 \\
\hline U.K. & 34 & 36 & 23 & 27 & 6 & 7 & 0 & 3 & 5 & 2 \\
\hline Others & 38 & 33 & 17 & 16 & 2 & 2 & 1 & 3 & 1 & 2 \\
\hline Japan & 125 & 88 & 12 & 12 & 5 & 3 & 5 & 9 & 1 & 0 \\
\hline U.S. & 120 & 152 & 66 & 81 & 24 & 30 & 9 & 37 & 10 & 27 \\
\hline ROW & 7 & 13 & 3 & 1 & 0 & 2 & 0 & 2 & 0 & 2 \\
\hline Total & 482 & 437 & 179 & 206 & 53 & 62 & 19 & 71 & 20 & 49 \\
\hline
\end{tabular}

SOURCE: Authors' own analyses.

NOTES: EU is European Union. ROW is rest of world.

clearly lagged behind EU firms as the region of first launch in every NCE category from 1982 to 1992 (Exhibit 5). Specifically, U.S. firms accounted for only 12 percent of first launches of global NCEs and 26 percent of first-in-class NCEs, even though U.S. firms accounted for more first-in-class drugs than EU firms during this period (Exhibit 4). The EU was the region of choice for first launches, accounting for more than 50 percent across all classes (except for biotech drugs) from 1982 to 1992.
The situation changed completely in 19932003, with the United States overtaking EU countries in all categories except global NCEs. It is striking that the United States accounted for 68 percent of first-in-class launches, 45 percent of biotech launches, and 69 percent of orphan launches after 1993. The U.S. leadership position also held for non-U.S. NCEs (data not shown). This finding confirms that both foreign and domestic firms favored the U.S. market for first launch of important products.

\section{EXHIBIT 5}

First-Launch Country Of New Chemical Entities (NCEs), By Category And Time Period, 1982-1992 And 1993-2003

\begin{tabular}{|c|c|c|c|c|c|c|c|c|c|c|}
\hline \multirow[b]{2}{*}{ Country } & \multicolumn{2}{|c|}{ All NCEs } & \multicolumn{2}{|c|}{ Global NCEs } & \multicolumn{2}{|c|}{ First-in-class NCEs } & \multicolumn{2}{|c|}{ Biotech NCEs } & \multicolumn{2}{|c|}{ Orphan NCEs } \\
\hline & 82-92 & $93-03$ & 82-92 & 93-03 & 82-92 & $93-03$ & 82-92 & $93-03$ & 82-92 & $93-03$ \\
\hline EU total & 260 & 151 & 126 & 97 & 27 & 14 & 8 & 27 & 10 & 12 \\
\hline France & 37 & 9 & 10 & 4 & 3 & 1 & 0 & 0 & 0 & 1 \\
\hline Germany & 36 & 35 & 16 & 25 & 5 & 4 & 1 & 12 & 0 & 5 \\
\hline Italy & 55 & 17 & 11 & 4 & 2 & 1 & 0 & 2 & 2 & 1 \\
\hline Switzerland & 18 & 14 & 13 & 14 & 4 & 3 & 0 & 6 & 0 & 4 \\
\hline U.K. & 34 & 31 & 27 & 25 & 4 & 2 & 1 & 3 & 6 & 2 \\
\hline Others & 79 & 44 & 48 & 24 & 9 & 4 & 5 & 4 & 2 & 0 \\
\hline Japan & 143 & 95 & 16 & 11 & 5 & 3 & 6 & 9 & 0 & 0 \\
\hline U.S. & 44 & 156 & 22 & 83 & 14 & 42 & 5 & 32 & 9 & 34 \\
\hline ROW & 35 & 35 & 15 & 15 & 7 & 4 & 0 & 3 & 1 & 3 \\
\hline Total & 482 & 437 & 179 & 206 & 53 & 62 & 19 & 71 & 20 & 49 \\
\hline
\end{tabular}

SOURCE: Authors' own analyses.

NOTES: EU is European Union. ROW is rest of world. 


\section{Discussion}

- Productivity. Our finding that introductions of first-in-class and global NCEs increased moderately is relevant to analyses of $R \& D$ productivity. In particular, the picture of a pharmaceutical industry with sharply declining productivity must be qualified by the fact that the quality of NCEs has increased. This is consistent with rising average $R \& D$ costs for new drug introductions and increased global sales at least through the 1990s. ${ }^{31}$ It would be instructive to investigate $\mathrm{R} \& \mathrm{D}$ productivity using several complementary measures of product quality and importance. 32

Supply and demand. The apparent shift toward more-innovative NCEs is also consistent with demand-and supply-side changes in the industry. In the United States, the largest pharmaceutical market, the percentage of drugs covered by managed care plans rose dramatically in the 1990s. ${ }^{33}$ Plans used rebate programs, tiered formularies, and other tools to manage drug benefits. Consequently, innovative products with few close substitutes earn premium prices. In contrast, new molecules with multiple substitutes are subject to discounts and rebates. There is evidence that prices in other countries are subject to similar forces. ${ }^{34}$ Hence, there are greater incentives for firms to focus on distinctive new products. This is consistent with the relative growth in first-in-class and global NCEs.

On the supply side, capacity for innovation and U.S. leadership in the industry have been enhanced by growth in the biotech sector. Although biotech drugs accounted for only 4 percent of NCEs from 1982 to 1992, they accounted for 16 percent from 1993 to 2003. Oncology drugs (a key focus of biotech research) now represent the greatest number of first-in-class drugs. Furthermore, U.S. firms are the dominant source of biotech drugs, originating more than half of them from 1982 to 2003.

Both the pharmaceutical and biotech sectors have benefited from the complementary "ecosystem" of life science research activities and start-ups that has emerged during the past two decades. The institutional and market forces promoting these sectors (public support of basic biomedical research, favorable university technology-transfer policies, and established private and public equity markets) are most developed in the United States. ${ }^{35}$ However, other countries are closing the gap. Arguably, U.S. firms have benefited from U.S. leadership. Whether this will remain true is debatable, given the growth in international partnership arrangements, a market or licensing system that is more global than in the past, and the establishment of R\&D facilities in the United States by foreign-owned firms.

Another finding from our analysis involves the strong shift toward the United States as the country of initial global launch. The fact that the United States has become the leading market in first-in-class, biotech, and orphan drug launches has obvious benefits for U.S. patients. At the same time, innovative NCEs may be subject to above-average risks compared to less innovative ones. ${ }^{36}$ Risks of new drugs will not become fully known until after widespread use. Thus, it is important to develop a diligent postmarketing surveillance system to monitor such risks and to educate physicians as information becomes available.

- Policy considerations. It is also relevant to consider policy developments on the horizon that could alter the U.S. competitive environment in pharmaceuticals. Such an inquiry is subject to uncertainties; however, some policy issues are worth mentioning in this regard. First, the current ban on National Institutes of Health (NIH) funding for research using additional stem cell lines compromises U.S. firms' research activities and leadership in an important research area. ${ }^{37}$

A second concern is the recent wave of litigation involving early patent challenges for commercially successful, innovative prod ucts. $^{38}$ These early patent challenges increase litigation costs and uncertainties for innovators and could upset the delicate balance fostered by the Hatch-Waxman Act between innovative and imitative competition. The EU provides ten years of data exclusivity as a quid pro quo for innovators bearing large up-front 
research and development costs. The U.S. provision offers only five years of protection.

A third development is the Medicare Part D prescription drug benefit. Although this program should lead to greater prescription drug use in the near term, budgetary pressures could have adverse consequences if drug price controls (or drug reimportation) are enacted. The evolution of Medicaid is instructive in this regard. As budgetary pressures have increased, states have implemented a variety of tools to bring down drug prices for Medicaid recipients. ${ }^{39}$ It remains to be seen how similar forces will play out for Medicare, but the history of large government payers' programs is not promising for drug innovators.

Nevertheless, there are recent positive developments in the U.S. market. In particular, there was an increase in new drug approvals by the FDA in 2004, reversing the downward trend of the past several years. ${ }^{40}$ Drug R\&D spending is growing at a double-digit rate, and the pipeline of clinical trial candidates is expanding. ${ }^{41}$ For the foreseeable future, the U.S. market is likely to provide more incentives for innovation than Europe or Japan.

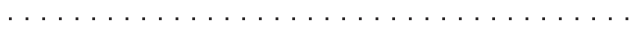

This study was supported in part by Astrazeneca but

does not represent its views. The analysis and

interpretation were performed independently by the

authors.

\section{NOTES}

1. National Academy of Engineering, The Competitive Status of the U.S. Pharmaceutical Industry (Washington: National Academies Press, 1983).

2. H. Grabowski, "An Analysis of U.S. International Competitiveness in Pharmaceuticals," Managerial and Decision Economics 10, no. 1 (1989): 27-33; L.G. Thomas, "Implicit Industrial Policy: The Triumph of Britain and the Failure of France in Global Pharmaceuticals," Industrial and Corporate Change 3, no. 2 (1994): 451-489; and L.G. Thomas III, The Japanese Pharmaceutical Industry (Cheltenham, England: Edgar Elgar, 2001).

3. Grabowski, "An Analysis," 29-30.

4. Ibid. The U.S. share of global NCEs was 38.2 percent from 1982 to 2002.

5. Ibid.

6. A. Gambardella, L. Orsenigo, and F. Pammolli, "Global Competitiveness in Pharmaceuticals: A
European Perspective" (Luxembourg: Office for Official Publications of the European Communities, 2001).

7. D. Dranove and D. Meltzer, "Do Important Drugs Reach the Market Sooner?" RAND Journal of Economics 25, no. 3 (1994): 402-429. Some of these measures are more feasible than others to employ on a global basis.

8. Although drug novelty is a separate quality indicator from therapeutic importance, the two are positively related. In particular, 57 percent of first-in-class drugs received FDA priority status, compared with 40 percent for other drugs.

9. H. Grabowski "Are the Economics of Pharmaceutical R\&D Changing? Productivity, Patents, and Political Pressures," PharmacoEconomics 22, Supp. 2 (2004): 15-24.

10. Biotech drug sales grew 17 percent in 2004, compared with 8.3 percent for overall U.S. drug sales. IMS Health, "IMS Reports 8.3 Percent Dollar Growth in 2004 U.S. Prescription Sales," Press Release, 14 February 2005, http://www .imshealth.com/ims/portal/front/articleC/ 0,2777,6599_3665_70069264,00.html (accessed 8 December 2006).

11. In particular, 78 percent of the orphan drugs in our sample received an FDA priority rating, compared with 39 percent for nonorphan drugs.

12. W.M. Wardell, "The Drug Lag Revisited: Comparison by Therapeutic Area of Patterns of Drugs Marketed in the United States and Great Britain from 1972 through 1976," Clinical Pharmacology and Therapeutics 24, no. 5 (1978): 449-524; and K.I. Kaitin and J.S. Brown, "A Drug Lag Update," Drug Information Journal 29, no. 2 (1995): 361-373.

13. E.R. Berndt et al., "Industry Funding of the FDA: Effects of PDUFA on Approval Times and Withdrawal Rates," Nature Reviews: Drug Discovery 4, no. 7 (2005): 545-554.

14. Ibid.

15. E.M. Healy and K.I. Kaitin, "The European Agency for the Evaluation of Medicinal Products' Centralized Procedure for Product Approval: Current Status," Drug Information Journal 33, no. 4 (1999): 969-978.

16. IMS Health, Global Pharmaceutical Review (Plymouth Meeting, Pa.: IMS Health, October 2004).

17. P. Danzon and L. Chao, "Does Regulation Drive Out Competition in the Pharmaceutical Markets?" Journal of Law and Economics (October 2000): 311-357.

18. P. Danzon, Y.R. Wang, and L. Wang, "The Impact of Price Regulation on the Launch Delay of New Drugs-Evidence from Twenty-five Major Markets in the 1990s," Health Economics 14, no. 3 (2005): 269-292; K.I. Kaitin and C. Cairns, "The 
New Drug Approvals of 1999, 2000, and 2001: Drug Development Trends a Decade after Passage of the Prescription Drug User Fee Act of 1992," Drug Information Journal 37, no. 3 (2003): 357-371; and M. Kyle, "Pharmaceutical Price Controls and Entry Strategies," Review of Economics and Statistics (forthcoming).

19. U.S. Food and Drug Administration, Center for Drug Evaluation and Research, CDER Report to the Nation: 2004, http://www.fda.gov/cder/reports/ rtn/2004/rtn2004.htm (accessed 10 January 2006).

20. IMS Health, IMS Retail Drug Monitor, Twelve Months to December 2003 (Plymouth Meeting, Pa.: IMS Health, 2004).

21. The USC and ATC systems are similar for many therapeutic classes, but they exhibit a few important differences. For example, the USC fails to separate triptans from older migraine drugs, and the ATC fails to separate selective serotonin uptake inhibitors (SSRIs) from tricyclic antidepressants. Some NCEs are first-in-class in more than one class; we used only the earliest class to avoid double counting.

22. The fact that we excluded first-in-class drugs that are not yet available in the United States should not affect our results materially. There are strong economic incentives to introduce important drugs in the United States with short time lags.

23. Martindale, The Complete Drug Reference, 1982-2003 eds. (London: Pharmaceutical Press, various years).

24. Our method might overestimate U.S. firms' output of NCEs if an NCE patented by a foreign firm is licensed to a U.S. firm and the first launch is in the United States. We checked the launch of first-in-class NCEs in the G7 countries against the first global launch and found no such case.

25. Percentages of global NCEs are underestimates for recent NCEs because of right censoring.

26. Grabowski, "An Analysis."

27. See Kaitin and Cairns, "The New Drug Approvals of 1999, 2000 and 2001," and the analyses of U.S. new drug approvals for earlier periods cited therein. For a few years (such as 1996), the number of NME approvals by the FDA exceeded the number of worldwide launches. However, the FDA's definition includes some categories that are not included in the IMS definition of NCEs. Second, many drugs have their worldwide launch outside the United States. Third, the U.S. peak in FDA approvals in 1996 in particular reflected uncertainty about the pending renewal of PDUFA.

28. Data for 2002 and 2003 are omitted from Exhibit 2 (see Exhibit 2 Notes). We do include these values in the eleven-year-interval comparisons dis- cussed above.

29. J. DiMasi, H. Grabowski, and J. Vernon, "R\&D Costs and Returns by Therapeutic Category," Drug Information Journal 38, no. 3 (2004): 211-223.

30. U.S. firms benefited from this earlier passage of the orphan drug legislation (1983) compared with Japan (1993) or the EU (1999). Also, the United States has a higher prevalence standard for orphan-drug status and more generous tax incentives. H.E. Kettler, Narrowing the Gap between Provision and Need for Medicines in Developing Countries (London: Office of Health Economics, 2000), 4043.

31. J.A. DiMasi, R.W. Hansen, and H.G. Grabowski, "The Price of Innovation: New Estimates of Drug Development costs," Journal of Health Economics 22, no. 2 (2003): 151-185; and H. Grabowski, J. Vernon, and J.A. DiMasi, "Returns on Research and Development for 1990s New Drug Introductions," PharmcoEconomics 20, Supp. 3 (2002): 1129.

32. Dranove and Meltzer, "Do Important Drugs Reach the Market Sooner?"

33. E.R. Berndt, "Pharmaceuticals in U.S. Health Care: Determinants of Quantity and Price," Journal of Economic Perspectives 16, no. 4 (2002): 45-66.

34. J. Calfee, "The Determinants of Pharmaceutical Price Disparities among Developed Countries" (Unpublished paper, American Enterprise Institute, May 2005).

35. F.M. Scherer, "New Perspectives on Economic Growth and Technological Innovation" (Washington: Brookings Institution, 1999).

36. M.K. Olson, "Are Novel Drugs Less Risky for Patients than Less Novel Drugs?" Journal of Health Economics 23, no. 6 (2004): 1135-1158.

37. G. Cook, "U.S. Stem Cell Research Lagging: Without Aid, Work Moving Overseas," Boston Globe, 23 May 2004.

38. Grabowski, "Are the Economics of Pharmaceutical R\&D Changing?"

39. Ibid.

40. FDA, CDER Report to the Nation.

41. Pharmaceutical Research and Manufacturers of America, "R\&D Investment by Pharmaceutical Companies Tops \$38 Billion in 2004," Press Release, 18 February 2005, http://www.phrma.org/ mediaroom/press/releases/18.02.2005.1128.cfm (accessed 8 December 2005). 